\title{
Evaluation of Different Ultrasonographic Modalities in the Diagnosis of Morbidly Adherent Placenta: A Cross-Sectional Study
}

\author{
Mostafa Hussein, Mohammed F. Ramadan, Ahmad M. Abu-Elhassan, Ahmed M. Abbas*, \\ Alaa Eldin A. Youssef \\ Department of Obstetrics \& Gynecology, Faculty of Medicine, Assiut University, Assiut, Egypt \\ Email: ^bmr90@hotmail.com
}

How to cite this paper: Hussein, M., Ramadan, M.F., Abu-Elhassan, A.M., Abbas, A.M. and Youssef, A.E.A. (2019) Evaluation of Different Ultrasonographic Modalities in the Diagnosis of Morbidly Adherent Placenta: A Cross-Sectional Study. Open Journal of Obstetrics and Gynecology, 9, 405-416.

https://doi.org/10.4236/ojog.2019.94041

Received: March 8, 2019

Accepted: March 29, 2019

Published: April 1, 2019

Copyright $\odot 2019$ by author(s) and Scientific Research Publishing Inc. This work is licensed under the Creative Commons Attribution International License (CC BY 4.0).

http://creativecommons.org/licenses/by/4.0/

\begin{abstract}
Objective: To compare the accuracy of different ultrasonographic modalities; two-dimensional ultrasound (2D-US), color Doppler and three-dimensional power Doppler (3D-PD) in the antenatal diagnosis of the morbidly adherent placenta. Setting: Obstetrics and Gynecology Department, Faculty of Medicine, Assiut University, Assiut, Egypt. Study Design: A cross-sectional study. Methods: All patients fulfill the inclusions criteria: gestational age $>28$ weeks, previous one or more cesarean delivery, previous uterine surgery, placenta previa, vitally stable patient and women accepted to participate in the study were included. All patients were evaluated using 2D-US, color Doppler and 3D-PD before delivery. The final diagnosis was established by laparotomy and by histopathology of hysterectomy sample if hysterectomy would be done. Results: One-hundred fifty patients were enrolled in the study. 2D-US has higher sensitivity $(86.96 \%)$ than $2 \mathrm{D}$ color Doppler $(84.06 \%)$ and 3D-PD (79.71\%) in the diagnosis of placenta accreta. On the other hand, 3D-PD has slightly higher specificity (83.95\%) than color Doppler (82.72\%) and 2D-US (77.78\%) in the diagnosis of placenta accreta. The most sensitive parameter in 2D-Us was the loss of retroplacental sonolucent zone (86.96\%). As regards color Doppler, the most sensitive parameter was the hypervascularity of the uterine-bladder interface (84.06\%). Tortuous vascularity with chaotic branching was the most sensitive parameter in 3D-PD with a sensitivity of $82.61 \%$. Conclusions: The use of 3D power Doppler with both 2D-US and color Doppler as complementary techniques could improve the antenatal diagnosis or exclusion of morbidly adherent placenta.
\end{abstract}

\section{Keywords}

Color Doppler, 3D-Power Doppler, Placenta Accreta, Morbidly Adherent 
Placenta

\section{Introduction}

Adherent placenta, including placenta accreta, placenta increta, and percreta, occurs as a result of placental villi penetrating the myometrium through a defect in the decidua basalis. It is a major cause of obstetric hemorrhage and is thus associated with increased maternal morbidity and mortality [1].

Comstock et al., 2004 reported that ultrasound examination during the second and third trimesters provides the most reliable data to be used in diagnosing placenta accreta [2]. The incidence of placenta accreta has increased with the rising number of cesarean deliveries. Current estimates indicate a $25 \%$ to $50 \%$ incidence of placenta accreta in patients with placenta previa and prior cesarean delivery (CD) [3]. The risk of placenta accreta is $3 \%, 11 \%, 40 \%, 61 \%$ and $67 \%$ for the first, second, third, fourth and fifth or greater repeat cesarean deliveries, respectively [4]. Besides advanced maternal age and multiparity, reported risk factors include any condition resulting in myometrial tissue damage followed by a secondary collagen repair, such as previous myomectomy, and endometrial defects due to vigorous curettage resulting in Asherman syndrome [5], submucous fibroids, thermal ablation [6], and uterine artery embolization [7].

Prenatal diagnosis of placenta accreta can help minimize the complication rate by enabling a surgeon to plan for the type of resources needed at the time of delivery which include obstetric anesthesia, appropriate surgical expertise, available blood products, and cell saver technology, possibly interventional radiology for uterine artery embolization, and postoperative intensive care.

A normal placental attachment site is characterized by a hypoechoic boundary between the placenta and the bladder. The ultrasonographic features suggestive of placenta accreta include irregularly shaped placental lacunae (vascular spaces) within the placenta, thinning of the myometrium overlying the placenta, loss of retroplacental clear space, protrusion of the placenta into the bladder, increased vascularity of the uterine serosa-bladder interface, and turbulent blood flow through the lacunae on Doppler ultrasonography [8] [9].

Therefore, the aim of the current study was to compare the accuracy of different ultrasonographic modalities; two-dimensional ultrasound (2D-US), color Doppler and three-dimensional power Doppler (3D-PD) in the antenatal diagnosis of morbidly adherent placenta.

\section{Patients and Methods}

This is a cross-sectional study conducted at Advanced Fetal Care Unit, Women's Health Hospital, Assiut University, Egypt between 1/1/2016 to 31/1/2018 and included 150 patients fulfilling the inclusions criteria: gestational age $>28$ weeks, previous one or more $\mathrm{CD}$, previous uterine surgery, placenta previa, vitally sta- 
ble patient and women accepted to participate in the study. Exclusion criteria were primigravida, patient not vitally stable or in attack of bleeding and those refused to participate in the study.

\section{Data collection:}

Data were recorded in a sheet include hospital number of the case, age, education, residence, occupation, consanguinity, gravidity, parity, previous pregnancy complications, gestational age, height, weight, and educational level.

\section{Test methods:}

We enrolled all women with placenta previa diagnosed by abdominal ultrasound after 28 weeks of gestation at the obstetric outpatient clinic or inpatient obstetric department of the aforementioned hospital. The study was approved by the Ethical Committee of Faculty of Medicine, Assiut University. All participants signed a written consent after reading the patient information sheet or having it read upon her.

Women with placenta previa found eligible for the study underwent an abdominal ultrasound, and the whole placenta was scanned in a systematic fashion using 2D-US, color Doppler ultrasound, and 3D-PD ultrasound. The placenta was imaged with a sufficient bladder volume to clearly visualize the serosa-bladder interface, and the angle of insonation will be kept as low as possible. The resistance index of flow within the abnormal lacunae and any newly formed vessels over the serosa-bladder border was measured in at least three different locations to obviate selection bias, with the lowest value being used for analysis.

On gray-scale ultrasound imaging, we considered the presence of at least two of the following characteristics to indicate focal placenta accreta and the presence of all of the following characteristics to indicate total placenta accreta:

1) Complete loss of the retroplacental sonolucent zone.

2) Irregular retroplacental sonolucent zone.

3) Thinning or disruption of the hyperechoic uterine serosa-bladder interface.

4) The presence of focal exophytic masses invading the urinary bladder.

5) The presence of abnormal placental lacunae [10].

Likewise, the diagnosis of placenta accreta was regarded as positive when any two of these power Doppler criteria is present and the presence of all of the following characteristics to indicate total placenta accreta:

1) Diffuse or focal lacunar flow pattern.

2) Sonolucent vascular lakes with turbulent flow typified by high velocity (peak systolic velocity $>15 \mathrm{~cm} / \mathrm{s}$ ) and low resistance waveform.

3) Hypervascularity of the uterine-bladder interface with abnormal blood vessels linking the placenta to the bladder.

4) Markedly dilated vessels over the peripheral subplacental region [10].

Then we examined patients by 3D-PD. To analyze the angioarchitecture of the lower uterine segment and placenta, we carried out a 3D-PD examination targeted to this region. Three to five 3D volumes were obtained in automatic sweeps using a motorized curved-array transducer while the women hold their breath. To interpret the data consistently, the settings of power, pulse repetition 
frequency, gain and wall motion filter were maintained for all examinations at $100 \%, 0.9 \mathrm{kHz},-5.4$ and low2, respectively. Offline image analysis will be performed using either the ultrasound platform (4D Views; Medison X8 Seoul, South Korea). Two views were successively evaluated: the lateral view was used to observe the intraplacental vasculature and serosa-bladder complex along the sagittal axis of the maternal pelvis, and the basal view illustrated the serosa-bladder interface in a $90^{\circ}$ rotation of the lateral view (observing from the direction of the bladder).

Since the abundant neovascularization of the uteroplacental region is a notable feature of placenta accreta, we further analyzed the patterns of placental vasculature in an attempt to differentiate between placenta previa totalis and focal placenta accreta. We made the diagnosis of placenta previa without accreta when the following 3D-PD criteria were demonstrated:

1) In the basal view, the vessels in the uterine serosa-bladder border were discretely arranged.

2) In the lateral view, both cotyledonal (fetal villous) circulation and intervillous (maternal) circulation were essentially parallel to each other, and perpendicular to the decidual plate.

3) The cotyledonal and intervillous circulations were separately distributed.

4) The cotyledonal circulation was longer and more apparent than the intervillous circulation.

Conversely, the diagnosis of placenta accreta and its variants was regarded as positive if at least two of the following 3D-PD criteria is illustrated in the lateral view and the presence of all of the following characteristics to indicate total placenta accreta:

1) Intraplacental hypervascularity.

2) Inseparable cotyledonal and intervillous circulations.

3) Tortuous vascularity with "chaotic branching". "Chaotic branching" is defined as vessels growing irregularly, with tortuous courses, varying calibers, and complex vessel arrangement, as seen in the tumoral vessels in ovarian malignancies. Furthermore, the basal view reveals numerous coherent vessels involving the serosa-bladder interface [10].

The sure diagnosis was established by Laparotomy and by histopathology of hysterectomy sample if hysterectomy would be done.

\section{Sample size calculation:}

Sample size was calculated using Epi-info program assuming that: Power of the study set at $80 \%$, Level of significance set at $5 \%(\mathrm{P}=0.05)$, Confidence interval 95\%, Underlying population prevalence of placenta accreta in patients with placenta previa established from the previous studies was $0.9 \%$ [3], Predetermined specificity of 2D-US and color Doppler from previous studies about $80 \%$ and acceptable increase in specificity after using $3 \mathrm{D}-\mathrm{PD}$ is $10 \%$. Accordingly, the sample size was set as 150 patients.

\section{Statistical analysis:}

Data were revised and analyzed by computer program SPSS (version 22). Data 
were expressed as descriptive number and percent (\%) of each variable and analytic data were expressed as mean $\pm \mathrm{SD}$. Chi-square test was used as a test of significance. $\mathrm{P}$-value $<0.05$ was considered to be significant. We calculated sensitivity, specificity, positive predictive value (PPV), negative predictive value (NPV) according to Receiver operating characteristic (ROC) for 2D-US, color Doppler and 3D-PD Ultrasonography features.

\section{Results}

After exclusion of 13 patients not met our inclusion criteria, 150 patients were enrolled in the final analysis of the results.

Table 1 shows that $34 \%$ of cases were from rural areas and $66 \%$ of cases from urban areas, about one-fifth of cases (19.3\%) were illiterate, $74 \%$ of cases were housewives as regard occupation. The mean age of cases was $28.91 \pm 5.26$ and the mean body mass index was $28.08 \pm 4.87$.

Table 2 shows a statistically significant difference in the final diagnosis of placenta accreta with increase gravidity, increase parity, increase the number of previous $\mathrm{CDs}$ and increase the number of living children. No statistically significant difference between the final diagnosis of placenta accreta and the number of previous abortions.

Table 3 shows that 2D-US has slightly higher sensitivity (86.96\%) than $2 \mathrm{D}$ color Doppler (84.06\%) and 3D-PD (79.71\%) in the diagnosis of placenta accreta. On the other hand, 3D-PD has slightly higher specificity (83.95\%) than 2D color Doppler $(82.72 \%)$ and 2D-US (77.78\%) in the diagnosis of placenta accreta.

Table 1. The basal characteristics of the study participants.

\begin{tabular}{|c|c|c|}
\hline & No. (150) & $\%$ \\
\hline \multicolumn{3}{|l|}{ Age: (years) } \\
\hline$<30$ & 78 & 52.0 \\
\hline$\geq 30$ & 72 & 48.0 \\
\hline Mean \pm SD (Range) & \multicolumn{2}{|c|}{$28.91 \pm 5.26(18.0-42.0)$} \\
\hline \multicolumn{3}{|l|}{ Residence: } \\
\hline Urban & 51 & 34.0 \\
\hline Rural & 99 & 66.0 \\
\hline \multicolumn{3}{|l|}{ Occupation: } \\
\hline Working & 39 & 26.0 \\
\hline Not working & 111 & 74.0 \\
\hline \multicolumn{3}{|l|}{ Education: } \\
\hline Illiterate & 29 & 19.3 \\
\hline Basic education & 23 & 15.3 \\
\hline Secondary & 48 & 32.0 \\
\hline High education & 50 & 33.3 \\
\hline
\end{tabular}




\section{Continued}

Consanguinity:

Yes

60.0

No

Husband occupation:

Employee

Farmer

Skilled worker

Husband education:

Illiterate

22

Basic education

Secondary

30.0

High education

45

Husband smoking:

Smoker

Non-smoker

Body mass index: (BMI)

Normal
Overweight
Obese

Mean \pm SD (Range)
76.0

$36 \quad 24.0$

$44 \quad 29.3$

$41 \quad 27.3$

65

$28.08 \pm 4.87(19.0-37.0)$

Table 2. Relationship between final diagnosis of placenta accreta and obstetric history of the study participants.

\begin{tabular}{|c|c|c|c|c|c|c|c|}
\hline & \multicolumn{6}{|c|}{ Final diagnosis } & \multirow{3}{*}{ P-value } \\
\hline & \multicolumn{2}{|c|}{$\begin{array}{c}\text { No placenta } \\
\text { accreta }\end{array}$} & \multicolumn{2}{|c|}{$\begin{array}{c}\text { Focal placenta } \\
\text { accreta }\end{array}$} & \multicolumn{2}{|c|}{$\begin{array}{c}\text { Total placenta } \\
\text { accreta }\end{array}$} & \\
\hline & No. & $\%$ & No. & $\%$ & No. & $\%$ & \\
\hline \multicolumn{8}{|l|}{ Gravidity: } \\
\hline $2-3$ & 38 & 46.9 & 15 & 29.4 & 0 & 0.0 & \multirow{3}{*}{$0.003^{*}$} \\
\hline $4-5$ & 23 & 28.4 & 17 & 33.3 & 10 & 55.6 & \\
\hline$>5$ & 20 & 24.7 & 19 & 37.3 & 8 & 44.4 & \\
\hline \multicolumn{8}{|l|}{ Parity: } \\
\hline $1-2$ & 45 & 55.6 & 20 & 39.2 & 0 & 0.0 & \multirow{3}{*}{$0.001^{*}$} \\
\hline $3-4$ & 26 & 32.1 & 23 & 45.1 & 12 & 66.7 & \\
\hline 5 or more & 10 & 12.3 & 8 & 15.7 & 6 & 33.3 & \\
\hline \multicolumn{8}{|c|}{ Number of abortions: } \\
\hline None & 56 & 69.1 & 28 & 54.9 & 11 & 61.1 & \multirow[t]{2}{*}{0.557} \\
\hline One & 13 & 16.0 & 11 & 21.6 & 4 & 22.2 & \\
\hline
\end{tabular}




\section{Continued}

\begin{tabular}{cccccccc}
\hline $\begin{array}{c}\text { Two or more } \\
\begin{array}{c}\text { Number of previous cesarean } \\
\text { sections: }\end{array}\end{array}$ & 12 & 14.8 & 12 & 23.5 & 3 & 16.7 & \\
$\quad$ One & & & & & & & \\
Two & 31 & 38.3 & 16 & 31.4 & 0 & 0.0 & $0.001^{*}$ \\
Three or more & 26 & 32.1 & 13 & 25.5 & 3 & 16.7 & \\
Number of living children: & 24 & 29.6 & 22 & 43.1 & 15 & 83.3 & \\
$<3$ & 45 & 55.6 & 25 & 49.0 & 2 & 11.1 & $0.003^{*}$ \\
$\geq 3$ & 36 & 44.4 & 26 & 51.0 & 16 & 88.9 & \\
\hline
\end{tabular}

*Statistically significant difference.

Table 3. Sensitivity, specificity, positive predictive value, negative predictive value, accuracy and area under the curve of different ultrasonographic modalities in the antenatal diagnosis of morbidly adherent placenta.

\begin{tabular}{|c|c|c|c|c|c|c|}
\hline & Sensitivity & Specificity & PPV & NPV & Accuracy & AUC \\
\hline \multicolumn{7}{|l|}{ 2D-ultrasound: } \\
\hline Loss of retroplacental sonolucent zone & 86.96 & 50.62 & 60.0 & 82.0 & 67.33 & 0.688 \\
\hline $\begin{array}{l}\text { Irregular retroplacental sonulcent } \\
\text { zone }\end{array}$ & 85.51 & 59.26 & 64.1 & 82.8 & 71.33 & 0.724 \\
\hline Abnormal placental lacunae & 76.81 & 82.72 & 79.1 & 80.7 & 80.00 & 0.798 \\
\hline $\begin{array}{l}\text { Thinning or disruption of hyperechoic } \\
\text { serosa-bladder interface }\end{array}$ & 75.36 & 81.48 & 77.6 & 79.5 & 78.67 & 0.784 \\
\hline $\begin{array}{l}\text { Presence of focal exophytic masses } \\
\text { invading the urinary bladder }\end{array}$ & 28.99 & 100.00 & 100.0 & 62.3 & 67.33 & 0.645 \\
\hline Initial diagnosis & 86.96 & 77.78 & 76.9 & 87.5 & 82.00 & 0.824 \\
\hline \multicolumn{7}{|l|}{ Color Doppler: } \\
\hline Diffuse or focal lacunar flow pattern & 81.16 & 77.78 & 75.7 & 82.9 & 79.33 & 0.795 \\
\hline $\begin{array}{l}\text { Sonolucent vascular lakes with } \\
\text { turbulent flow }\end{array}$ & 81.16 & 81.48 & 78.9 & 83.5 & 81.33 & 0.813 \\
\hline $\begin{array}{l}\text { Hypervascularity of the } \\
\text { uterine-bladder interface }\end{array}$ & 84.06 & 49.38 & 58.6 & 78.4 & 65.33 & 0.667 \\
\hline $\begin{array}{l}\text { Markedly dilated vessels over the } \\
\text { peripheral sub-placental region }\end{array}$ & 71.01 & 90.12 & 86.0 & 78.5 & 81.33 & 0.806 \\
\hline Initial diagnosis & 84.06 & 82.72 & 80.6 & 85.9 & 83.33 & 0.834 \\
\hline \multicolumn{7}{|l|}{ 3D-Power Doppler: } \\
\hline Intra-placental hypervascularity & 79.71 & 80.25 & 77.5 & 82.3 & 80.00 & 0.800 \\
\hline $\begin{array}{l}\text { Inseparable cotyledonal and } \\
\text { intervillous circulations }\end{array}$ & 76.81 & 82.72 & 79.1 & 80.7 & 80.00 & 0.798 \\
\hline $\begin{array}{l}\text { Tortuous vascularity with chaotic } \\
\text { branching }\end{array}$ & 82.61 & 92.59 & 90.5 & 86.2 & 88.00 & 0.876 \\
\hline Initial diagnosis & 79.71 & 83.95 & 80.9 & 82.9 & 82.00 & 0.818 \\
\hline
\end{tabular}

The most sensitive parameter in 2D-Us was the loss of retroplacental sonolucent zone (86.96\%) (Figure 1). As regards color Doppler, the most sensitive pa- 
rameter was the hypervascularity of the uterine-bladder interface (84.06\%) (Figure 2 ). Tortuous vascularity with chaotic branching was the most sensitive parameter in 3D-PD with a sensitivity of $82.61 \%$ (Figure 3 ).

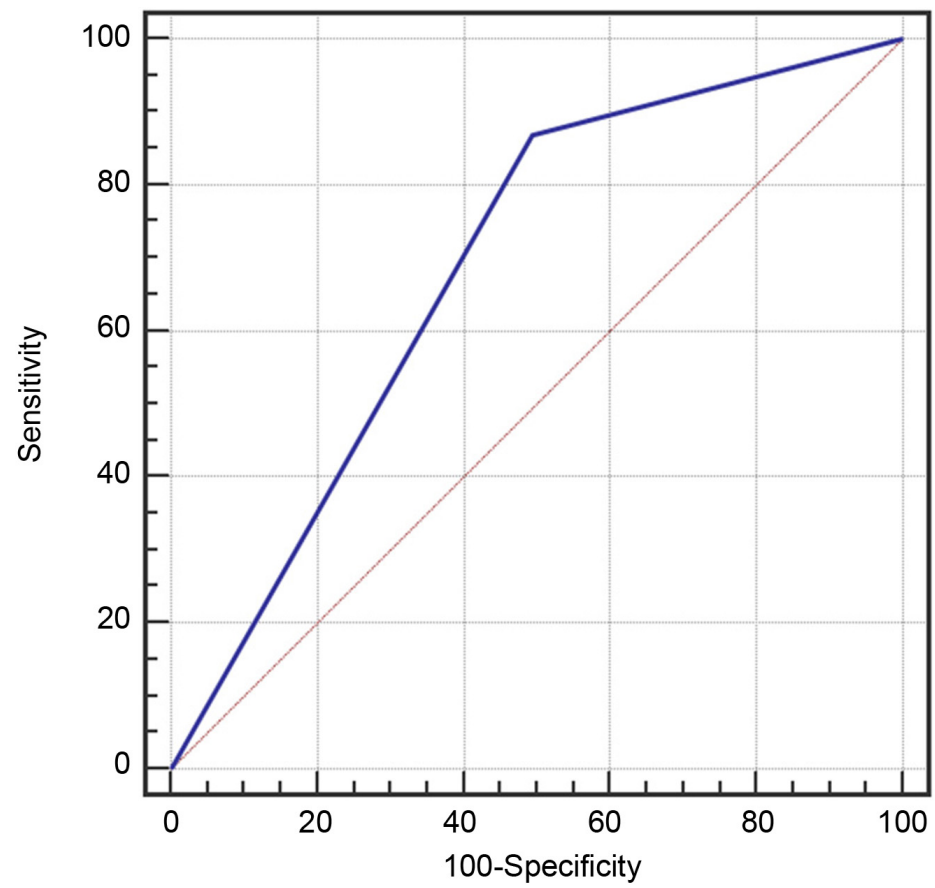

Figure 1. Receiver operating characteristic (ROC) curve for loss of retroplacental sonolucent zone in the diagnosis of placental accrete.

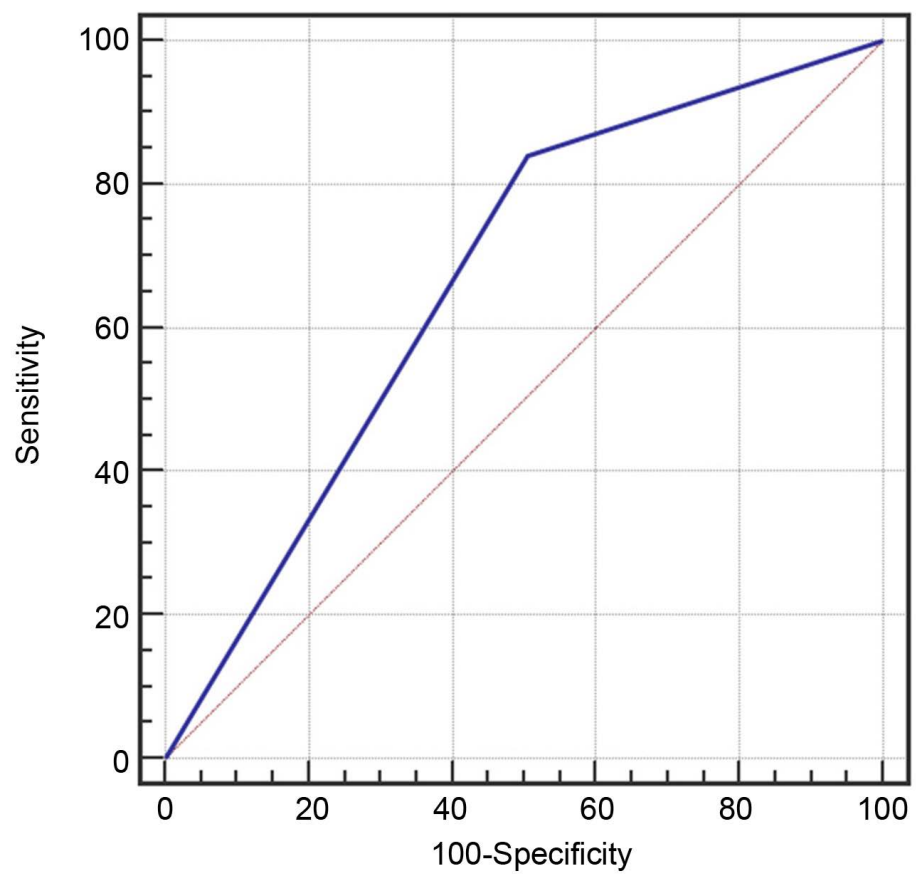

Figure 2. Receiver operating characteristic (ROC) curve for the presence of hypervascularity of the uterine-bladder interface by color Doppler in the diagnosis of placental accreta. 


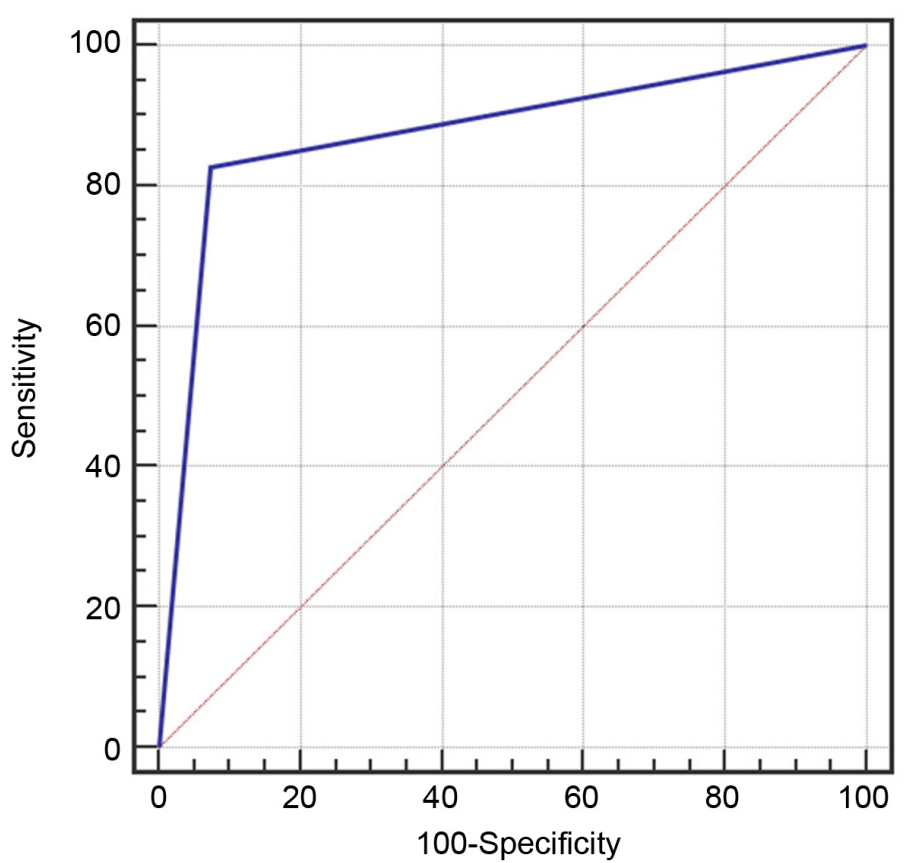

Figure 3. Receiver operating characteristic (ROC) curve for the presence of tortuous vascularity with chaotic branching by $3 \mathrm{D}-\mathrm{PD}$ in the diagnosis of placental accrete.

\section{Discussion}

Ultrasonography with grayscale and color Doppler imaging is the first recommended modality for diagnosing morbidly adherent placenta [11]. Although more elaborate forms of imaging are promising in defining the topography of the placenta, such as 3-dimensional Doppler and volume contrast ultrasound, validation studies, as well as generalized applicability of technique, are lacking [10].

A recent meta-analysis of 23 studies explored the contribution of these ultrasound parameters to the overall prediction of morbidly adherent placenta and found a promising sensitivity of $91 \%$ and specificity of $97 \%$ [12]. A logical next step in predicting morbidly adherent placenta by ultrasound is to determine the significance of each ultrasound finding to estimate the probability of invasion based on a multi-parametric analysis. Rac et al., 2014 developed a predictive equation for the probability of invasion based on a combination of ultrasound parameters and clinical characteristics in a cohort study of the women at increased risk for placental invasion [13].

In the present study, the mean age of the patients was 28.91, and this was in accordance with Cali et al., 2013 [10]. Also, a statistically significant difference of final diagnosis of placenta accreta with increase gravidity, increase parity, increase the number of previous cesarean sections and increase the number of living children was detected and this was in accordance with Silver et al., 2006 [4].

In the present study, for 2D-US, loss of retroplacental sonolucent zone has the highest sensitivity of $86.96 \%$ yet an unsatisfactory PPV $60 \%$. Hence, despite detecting more true positives, its reliability in confirming placenta accreta is low, 
and thus it might lead to more unnecessary hysterectomies. In the current study the most effective 2D-US criteria was irregular retroplacental sonolucent zone with NPV of 82.8 and this in accordance with Cali et al., 2013 [10] while the most effective 2D color Doppler criteria was sonolucent vascular lakes with turbulent flow with NPV of 83.5\% and this was against Cali et al., 2013 [10] whose study showed that hypervascularity of the serosa bladder interface had the highest NPV.

The present work suggested that as regard 2D-US, loss/irregularity of retroplacental sonolucent zone between placenta and uterus should not be used as a single diagnostic criterion, but should be combined with other criteria with greater PPV as low PPV for loss/irregularity of retroplacental sonolucent zone between placenta and uterus $60 \%, 64.1 \%$ respectively was detected. Moreover, the data suggested that the lack of loss/irregularity of clear space might help to exclude the diagnosis of morbidly adherent placenta because they had the highest NPV.

This was supported by Finberg and Williams, 1992 [14] and Comstock, 2011 [15] who underlined that loss/irregularity of retroplacental sonolucent zone between placenta and uterus accounts for the majority of false positives and this criterion should not be used by itself to make a diagnosis. This suggested that if the retroplacental sonolucent area between the placenta and the uterus was preserved, morbidly adherent placenta was unlikely to occur with high NPV of $82 \%$, $82.8 \%$ respectively.

The current work showed that the presence of focal exophytic masses invading the urinary bladder had the highest PPV of $100 \%$. This was in agreement with Moniem et al., 2015 [16] but against Shih et al., 2009 [17] and Pilloni et al., 2016 [18] studies which showed that thinning or disruption of hyperechoic serosa-bladder interface had the highest PPV of $100 \%$ and $77.8 \%$ respectively while irregular retroplacental sonolucent zone had the highest NPV of $82.8 \%$ and this was in accordance with Pilloni et al., 2016 [18], but against Shih et al., 2009 [17] and Moniem et al., 2015 [16] whose study showed that disruption of serosa-bladder interface had the highest NPV of $73 \%$ and $84.1 \%$ respectively.

In the present study, sonolucent vascular lakes with turbulent flow had the highest NPV of 83.5\%, and this was in accordance with Finberg \& Williams, 1992 [14] and Pilloni et al., 2016 [18], but this was against Shih et al., 2009 [17] whose study showed that diffuse or focal lacunar flow pattern had the highest NPV of $75 \%$.

In the current study, tortuous vascularity with chaotic branching by $3 \mathrm{D}-\mathrm{PD}$ had the highest PPV and NPV of 90.5\%, 86.2\% respectively and this was against Moniem et al., 2015 [16] who showed that intra-placental hypervascularity has the highest PPV and NPV of 50\% and 100\% respectively. Shih et al., 2009 [17] study showed that tortuous vascularity with chaotic branching by 3D-PD had the highest PPV of $100 \%$ while intra-placental hypervascularity has the highest NPV of $89 \%$. 


\section{Conclusion}

The use of 2D-US has the highest NPV and sensitivity followed by the use of 2D color Doppler in the diagnosis of the morbidly adherent placenta, while the use of 3D-PD has the highest PPV and specificity followed by the use of 2D color Doppler in the diagnosis of the morbidly adherent placenta. Therefore, the use of 3D power Doppler with both 2D-US and color Doppler as complementary techniques could improve the antenatal diagnosis or exclusion of morbidly adherent placenta.

\section{Conflicts of Interest}

The authors declare that they have no conflict of interest.

\section{References}

[1] Miller, D., Chollet, J. and Goodwin, T. (1997) Clinical Risk Factors for Placenta Previa-Placenta Accreta. American Journal of Obstetrics and Gynecology, 177, 210-214. https://doi.org/10.1016/S0002-9378(97)70463-0

[2] Comstock, C.H., Love, J.J., Bronsteen, R.A., Lee, W., Vettraino, I.M., Huang, R.R., et al. (2004) Sonographic Detection of Placenta Accreta in the Second and Third Trimesters of Pregnancy. American Journal of Obstetrics and Gynecology, 190 1135-1140. https://doi.org/10.1016/j.ajog.2003.11.024

[3] Gielchinsky, Y., Rojansky, N., Fasouliotis, S. and Ezra, Y. (2002) Placenta Accreta-Summary of 10 Years: A Survey of 310 Cases. Placenta, 23, 210-214. https://doi.org/10.1053/plac.2001.0764

[4] Silver, R., London, M., Rouse, K., Spong, C., Thom, E., et al. (2006) Maternal Morbidity Associated with Multiple Repeat Cesarean Deliveries. Obstetrics and Gynecology, 107, 1226-1232. https://doi.org/10.1097/01.AOG.0000219750.79480.84

[5] Al-Serehi, A., Mhoyan, A., Brown, M., Benirschke, K., Hull, A. and Pretorius, D. (2008) Placcenta Accrete: An Association with Fibroids and Asherman Syndrome. Journal of Ultrasound in Medicine, 27, 1623-1628. https://doi.org/10.7863/jum.2008.27.11.1623

[6] Hamar, B., Wolff, E., Kodaman, P. and Marcovici, I. (2006) Premature Rupture of Membranes, Placenta Increta, and Hysterectomy in a Pregnancy Following Endometrial Ablation. Journal of Perinatology, 26, 135-137.

https://doi.org/10.1038/sj.jp.7211442

[7] Pron, G., Mocarrski, E., Bennett, J., Vilos, G., Common, A. and Vanderburgh, L. (2005) Pregnancy after Uterine Artery Embolization for Leiomyomata: The Ontario Multicenter Trial. Obstetrics and Gynecology, 105, 67-76. https://doi.org/10.1097/01.AOG.0000149156.07061.1f

[8] Comstock, C. (2005) Antenatal Diagnosis of Placenta Accrete: A Review. Ultrasound Obstetrics and Gynecology, 26, 89-96. https://doi.org/10.1002/uog.1926

[9] Warshak, C.R., Eskander, R., Hull, A.D., Scioscia, A.L., Mattrey, R.F., Benirschke, K., et al. (2006) Accuracy of Ultrasonography and Magnetic Resonance Imaging in the Diagnosis of Placenta Accreta. Obstetrics and Gynecology, 108, 573-581. https://doi.org/10.1097/01.AOG.0000233155.62906.6d

[10] Cali, G., Giambanco, L., Puccio, G. and Foriani, F. (2013) Morbidly Adherent Placenta: Evaluation of Ultrasound Diagnostic Criteria and Differentiation of Placenta 
Accreta from Placenta Percreta. Ultrasound Obstetrics and Gynecology, 41, 406-412. https://doi.org/10.1002/uog.12385

[11] American College of Obstetricians and Gynecologists (2012) Committee Opinion No. 529: Placenta Accreta. Obstetrics and Gynecology, 120, 207-211. https://doi.org/10.1097/AOG.0b013e318262e340

[12] D'Antonio, F., Iacovella, C. and Bhide, A. (2013) Prenatal Identification of Invasive Placentation Using Ultrasound: Systematic Review and Meta-Analysis. Ultrasound Obstetrics and Gynecology, 42, 509-517. https://doi.org/10.1002/uog.13194

[13] Rac, M.W., Dashe, J.S., Wells, C.E., Moschos, E., McIntire, D.D. and Twickler, D.M. (2015) Ultrasound Predictors of Placental Invasion: The Placenta Accreta Index. American Journal of Obstetrics and Gynecology, 212, 343.e1-e7.

[14] Finberg, H. and Williams, J. (1992) Placenta Accreta: Prospective Sonographic Diagnosis in Patients with Placenta Previa and Prior Cesarean Section. Journal of UItrasound in Medicine, 11, 333-343. https://doi.org/10.7863/jum.1992.11.7.333

[15] Comstock, C.H. (2011) The Antenatal Diagnosis of Placental Attachment Disorders. Current Opinion in Obstetrics and Gynecology, 23, 117-122. https://doi.org/10.1097/GCO.0b013e328342b730

[16] Moniem, A.M., Ibrahim, A., Akl, S.A., Aboul-Enen, L. and Abdelazim, I.A. (2015) Accuracy of Three-Dimensional Multislice View Doppler in Diagnosis of Morbid Adherent Placenta. Journal of The Turkish-German Gynecological Association, 16, 126-136. https://doi.org/10.5152/jtgga.2015.15038

[17] Shih, C.J., Jaraquemada, J.M.P., Su, Y.N., Shyu, M.K., et al. (2009) Role of ThreeDimensional Power Doppler in the Antenatal Diagnosis of Placenta Accreta: Comparison with Gray-Scale and Color Doppler Techniques. Ultrasound Obstetrics and Gynecology, 33, 193-203. https://doi.org/10.1002/uog.6284

[18] Pilloni, E., Alemanno, M., Gaglioti, P., Sciarrone, A., Garofalo, A., Biolcati, M., et al. (2016) Accuracy of Ultrasound in Antenatal Diagnosis of Placental Attachment Disorders. Ultrasound Obstetrics and Gynecology, 47, 302-307.

https://doi.org/10.1002/uog.14893 